\title{
Implementasi Teknologi NFC Untuk Akses Pintu Masuk dan Keluar
}

\author{
Ahmad Sadik Djamar, Sherwin R.U.A Sompie, M. Dwisnanto Putro \\ Teknik Informatika Universitas Sam Ratulangi Manado, Indonesia. \\ Ahmadsadik988@gmail.com, aldo@unsrat.ac.id,dwisnantoputro@unsrat.ac.id
}

\begin{abstract}
Abstrak - Keamanan dalam akses membuka pintu sebuah ruangan merupakan faktor yang sangat mempengaruhi akan pentingnya peranan kunci yang dapat memberikan keamanan pada ruangan. Kunci sangat dibutuhkan dalam suatu keamanan sebagai pengaman yang digunakan untuk membuka pintu ruangan. Pintu merupakan salah satu akses masuk dan keluar ruangan yang membutuhkan tingkat keamanan tinggi untuk mencegah tingkat pencurian dan kehilangan ketika ditinggal oleh pemiliknya, dan juga mencegah apabila kunci di duplikat banyak cara yang dilakukan untuk memenuhi kebutuhan tersebut.

Dalam penelitian ini memanfaatkan teknologi NFC ( Near Field Communication ) untuk akses pintu masuk dan keluar merupakan solusi untuk mengatasi masalah keamanan ruangan. Karena tag NFC memiliki id yang tidak dapat diduplikat beda dengan kunci pada umumnya. Sistem ini dibuat menggunakan mikrokontroler Arduino, NFC reader, selenoid doorlock untuk membuka pintu, dan LCD Untuk menampilkan nama dan id pengguna, Esp8266 untuk menghubungkan Arduino dengan server. Untuk menyimpan data log NFC via web server, dengan nama domain Ahmadsadiknfcskripsi.com. Dengan adanya penggunaan NFC di pintu masuk diharapkan orang yang masuk dan keluar ruangan dapat di - identifikasi terlebih dahulu sebelum diperbolehkan masuk atau keluar ruangan.

Penelitian ini menghasilkan aplikasi sistem akses pintu masuk dan keluar menggunakan $N F C$ yang bisa mengetahui waktu user masuk dan keluar ruangan,dan siapa saja yang memiliki hak untuk masuk dalam sebuah ruangan.
\end{abstract}

Kata kunci : NFC, Arduino UNO, Akses, Pintu Masuk, Webserver, Esp8266.

\section{PENDAHULUAN}

Near Field Communication (NFC) adalah salah satu teknologi komunikasi terbaru memanfaatkan gelombang radio. Teknologi Near Field Communication sampai sekarang semakin berkembangnya teknologi yang dimiliki mampu menggantikan beberapa peranan sistem yang sudah berjalan saat ini seperti pada proses pembayaran dan ticketing pada suatu ruangan-ruangan tertentu dibutuhkan kunci fisik saja tetapi sebuah kunci virtual yang mempunyai keamanan lebih dan dapat dikontrol oleh pemilik ruangannya.

Dengan semakin majunya teknologi dalam komunikasi data antar perangkat ini maka manfaat yang dihasilkan dari NFC makin beragam, bahkan beberapa diantaranya sudah mulai diterapkan diberbagai penjuru dunia. NFC sendiri menyederhanakan komunikasi data antar perangkat biasanya harus mengkoneksikan menggunakan Bluetooth maupun wifi yang memerlukan otentikasi dan penyamaan koneksi terlebih dahulu sebelum bisa digunakan dan biasanya memakan waktu yang cukup lama. Berbeda dengan NFC otentikasi antar perangkat dilakukan hanya beberapa detik saja. NFC beroperasi dalam radius sekitar 4 $\mathrm{cm}$ dan menyediakan koneksi nirkabel antara perangkat anda dan yang lain. Hal ini memungkinkan untuk komunikasi dua arah, dengan kedua perangkat yang terlibat mampu mengirim dan menerima informasi.

Keamanan dalam akses membuka pintu sebuah ruangan merupakan faktor yang sangat mempengaruhi akan pentingnya peranan kunci yang dapat memberikan keamanan pada ruangan. Kunci sangat dibutuhkan dalam suatu sistem keamanan sebagai pengaman yang digunakan dalam membuka pintu ruangan. Pada penelitian ini digunakan NFC tag sebagai kunci untuk akses masuk dan keluar sebuah ruangan. selain itu sistem ini juga dapat memberikan informasi kepada admin atau pengguna yang memiliki akses ke ruangan tersebut agar bisa mengetahui waktu user masuk dan keluar ruangan. Kebutuhan akan suatu sistem yang dapat memberikan keamanan sangat dibutuhkan banyak orang. Banyak cara yang dilakukan untuk memenuhi kebutuhan tersebut. Salah satunya memanfaaatkan teknologi pada sistem keamanan akses buka pintu. Pintu merupakan salah satu akses masuk dan keluar ruangan yang membutuhkan tingkat keamanan tinggi untuk mencegah tingkat pencurian atau kehilangan ketika di tinggal oleh pemiliknya. Dan juga mencegah apabila kunci di duplikat, karena tag NFC memiliki id yang berbeda dan tak bisa di duplikat. Maka dari itu memanfaatkan teknologi NFC merupakan solusi untuk mengatasi masalah keamanan ruangan.

\section{A. Near Field Communication}

II. LANDASAN TEOR

NFC (Near Field Communication) adalah sebuah teknologi terbaru dalam perpindahan data berbasis teknologi RFID (Radio Frequency Identification) yang menggunakan konektivitas tanpa kabel sehingga sangat memungkinkan komunikasi data antar perangkat elektronik dalam jarak dekat menggunakan perantara induksi medan magnet yang terdapat dalam perangkat elektronik tersebut. NFC juga memungkinkan penggunanya untuk melakukan transaksi secara contactless, sentuhan. NFC berkomunikasi via induksi medan magnet, dimana dua device terletak dalam area yang berdekatan yang secara efektif membentuk sebuah transformator dengan inti udara. NFC merupakan teknologi yang dapat menulis dan membaca data yang dilakukan dalam koneksi. Kecepatan transfer data yang dapat dilakukan menggunakan NFC beragam, antara lain $106 \mathrm{Kbps}, 212 \mathrm{Kbps}$ dan $424 \mathrm{Kbps}$. Keunikan dari NFC ini terletak pada kemampuannya untuk mengubah mode operasinya menjadi reader/writer, peer topeer, atau card emulation. [6] 
Cara kerja NFC yaitu pengguna harus mempunya chip NFC (NFC tag) dan menempelkan perangkat tersebut pada Alat pembaca NFC ( NFC Reader).

\section{B. Implementasi}

Implementasi dapat di artikan sebagai pelaksaan/penarapan. Menurut Nurdin Usman (2002) dalam bukunya yang berjudul "Konteks Implementasi Berbasis Kurikulum”, Implementasi adalah muara aktivitas, aksi, tindakan atau adanya mekanisme suatu sistem. Implementasi bukanlah sededar aktivitas, tetapi adalah suatu kegiatan yang terncana untuk mencapai tujuan kegiatan. Jeffri L. Pressman dan Aaron B.Wildaviski (Charles O.Jones, 1996) mengartikan Implementasi sebagai suatu proses interaksi antara suatu perangkat tujuan dan tindakan yang mampu untuk meraihnya. Implementasi adalah kemampuan membentuk hubungan-hubungan lebih lanjut dalam rangkaian sebab-akibat yang menghubungkan tindakan dengan tujuan. Dalam kenyataannya, implementasi adalah merupakan proses untuk melaksanakan ide, program, atau seperangkat aktivitas baru dengan harapan orang lain dapat menerima dan melakukan perubahan tersebut (Fulan, 2004). [3]

\section{Mikrokontroler}

Menurut Setiawan (2011) Mikrokontroler adalah suatu IC dengan kepadatan yang sangat tinggi, dimana semua bagian yang diperlukan untuk suatu kontroler sudah disatukan dalam satu keping, biasanya terdiri dari CPU (Central Processing Unit), RAM (Random Access Memory), EEPROM/EPROM/PROM/ROM, I/O, Serial \& Parallel, Timer, Interupt Controller dan berfungsi sebagai pengontrol rangkaian elektronik serta umunya dapat menyimpan program di dalamnya. [3]

\section{Arduino UNO R3}

Arduino adalah suatu perangkat prototype elektronik berbasis mikrokontroler dan open source, perangkat keras dan perangkat lunaknya mudah digunakan. perangkat ini ditujukan bagi siapapun yang tertarik/ memanfaatkan mikrokontroler secara praktik dan mudah. Bagi pemula dengan menggunakan board ini akan mudah mempelajari pengendalian dengan mikrokontroler, bagi desainer pengontrol menjadi lebih mudah dalam membuat prototype ataupun implementasi. Arduino dapat digunakan "mendeteksi" lingkuangan dengan menerima masukkan dari berbagai sensor (misal : cahaya, suhu, inframerah, ultrasonic,jarak,tekanan,kelembaban) dan dapat "mengendalikan" peralatan sekitarnya (misal: lampu, berbagai jenis motor, dan aktuor lainnya. Board arduino uno menggunakan mikrokontroler ATmega328. Secara umum posisi/letak pin-pin terminal $I / O$ pada berbagai board arduino posisinya sama dengan posisi/letak pin-pin terminal $I / O$ dari arduino yang mempunyai 14 pin digital yang dapat di set sebagai Input/Output (beberapa di antaranya mempunyai fungsi ganda). [5]

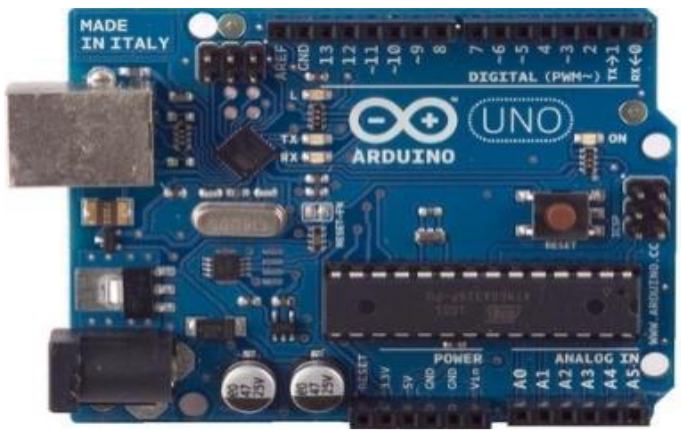

Gambar 1. Arduino Uno R3

\section{E. Arduino IDE}

Arduino IDE merupakan sebuah program untuk menuliskan kode sumber ke dalam mikrokontroler arduino. Arduino IDE menggunakan Software Processing yang digunakan untuk menulis program ke dalam arduino. Bahasa pemrogramannya sendiri merupakan penggabungan antara bahasa $C++$ dan java dikarenakan struktur bahasa pemrograman dan penggunaan library yang mirip dengan C++ dan java (Sulaiman, 2012). Software IDE arduino terdiri dari 3 (tiga) bagian :

1. Editor program, untuk menulis dan mengedit program dalam bahasa processing. Listing program pada Arduino disebut sketch.

2. Compiler, modul yang berfungsi mengubah bahasa processing (kode program) ke dalam kode biner karena kode biner adalah satu-satunya bahasa program yang dipahami oleh mikrokontroler.

3. Uploader, modul yang berfungsi memasukkan kode biner ke dalam memori mikrokontroller.

Struktur perintah pada arduino secara garis besar terdiri dari 2 (dua) bagian yaitu void setup dan void loop. Void setup berisi perintah yang akan dieksekusi hanya satu kali sejak arduino dihidupkan sedangkan void loop berisi perintah yang akan dieksekusi berulang-ulang selama arduino dihidupkan. [5]

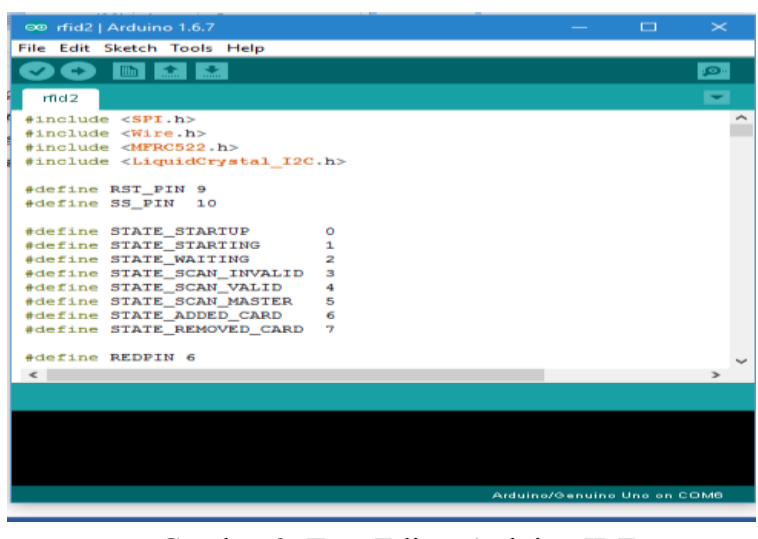

Gambar 2. Text Editor Arduino IDE

\section{F. Web Server}

Web server adalah sebuah software yang memberikan layanan berbasis data dan berfungsi menerima permintaan dari HTTP atau HTTPS pada klien yang dikenal dan biasanya kita kenal dengan nama web browser. (Mozilla Firefox, Google 
Chrome) dan mengirimkan kembali yang hasilnya dalam bentuk beberapa halaman web dan pada umumnya akan berbentuk dokumen html.

\section{G. Komunikasi Serial}

Komunikasi serial adalah proses pengiriman data bit per bit tiap satuan waktu, secara berurutan, melalui saluran komunikasi atau jalur bus komputer. Hal ini berbeda dengan komunikasi paralel, yang berbeda bit dikirim secara keseluruhan dalam satu waktu, melalui bebrapa data yang terhubung. Komunikasi serial digunakan untuk semua komunikasi jarak jauh dan jaringan komputer, dimana biaya kabel dan proses simkronisasi membuat komunikasi paralel tidak praktis.

\section{METODOLOGI PENELITIAN}

\section{A. Kerangka Pikir}

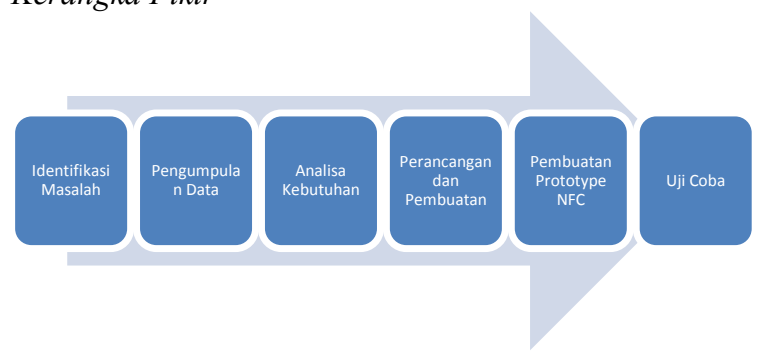

Gambar 3. Metodologi penelitian

\section{B. Identifikasi Masalah}

Keamanan dalam akses membuka pintu sebuah ruangan merupakan faktor yang sangat mempengaruhi akan pentingnya peranan kunci yang dapat memberikan keamanan pada ruangan. kunci sangat dibutuhkan dalam suatu sistem keamanan sebagai pengaman yang digunakan dalam membuka pintu. Maka dari itu pada penelitian ini digunakan NFC tag sebagai kunci untuk akses masuk dan keluar ruangan menggantikan kunci manual.

\section{Pengumpulan data}

Pengumpulan data yang dilakukan secara Studi literatur merupakan pengumpulan data memalui media buku, paper riset, maupun jurnal. Pada Tahap ini akan dilakukan penelusuran dan pembelajaran terhadap berbagai macam literature seperti buku, jurnal, skripsi, tugas akhir, dan referensi-referensi melalui internet yang berkaitan dengan pemrograman $C / C++$ untuk arduino,cara kerja alat yang akan digunakan dan Bahasa pemrograman PHP dan tools cPanel untuk tampilan web.

\section{Analisis kebutuhan}

Menganalisis kebutuhan yang diperlukan untuk melakukan penelitian, serta menganalis kebutuhan untuk membangun Prototype NFC. Penulis menggunakan alat penelitian berupa hardware untuk membangun prototype dan komputer untuk melakukan penulisan kode sumber program. Deskripsi alat penelitian yang digunakan dalam tahap penelitian adalah sebagai berikut:

\section{Hardware}
a. Arduino UNO R3
b. NFC reader $\mathrm{V} 3$
c. Selenoid DoorLock
d. LCD $16 \times 2$
e. Papan PCB (Printed Circuit Board)
f. Relay
g. Kabel Jumper
h. AC/DC Adaptor
i. $\quad$ Esp8266

2. Software dan tools
a. Arduino IDE 1.8.1

b. cPanel

\section{E. Perancangan dan Pembuatan}

Merancang Prototype NFC yang akan dibangun. Pada Tahap ini akan dilakukan pembuatan miniatur pintu untuk mensimulasikan cara kerja prototype NFC, kemudian melakukan penyambungan hardware agar saling terhubung dan terkoordinasi satu dengan yang lain, semua komponen prototype akan terhubung ke mikrokontroler. Selanjutnya melakukan penulisan kode sumber ke mikrokontroler, dan membuat aplikasi antar-muka untuk menampilkan informasi, menambah, dan menghapus data id tag NFC.

\section{a. Perancangan Antarmuka}

Untuk antarmuka atau GUI (Graphical User Interface) di bangun menggunakan cPanel, dengan Bahasa pemrograman PHP. Program memliki halaman login admin yang memiliki hak untuk mengakses website dengan alamat domain ahmadsadikNFCskripsi.com. Program dirancang menggunakan 4 (empat) buah form, yaitu :

1. Form utama untuk melihat history siapa dan waktu pengguna masuk dan keluar ruangan.

2. Form pengguna menambah, menghapus, dan edit data id yang telah terdaftar di dalam database.

3. Form mode untuk mengubah mode masuk dan keluar sesuai keinginan pengguna.

4. Form keluar untuk keluar dari administrator website dan kembali ke halaman login.

Untuk mengedit administrator web server menggunakan tools cPanel dengan mengetikkan http://ahmadsadikNFCskripsi .com:2082/dan memasukkan username : Ahmadsad dan password : 7hyHDg60g5

\section{F. Perancangan Sistem}

Secara garis besar cara kerja sistem ini dapat dilihat pada gambar 7 di bawah. Dimana bentuk masukan data (input) adalah kartu NFC tag, dan keluaran (output) adalah tampilan GUI, LCD, buzzer dan selenoid. 


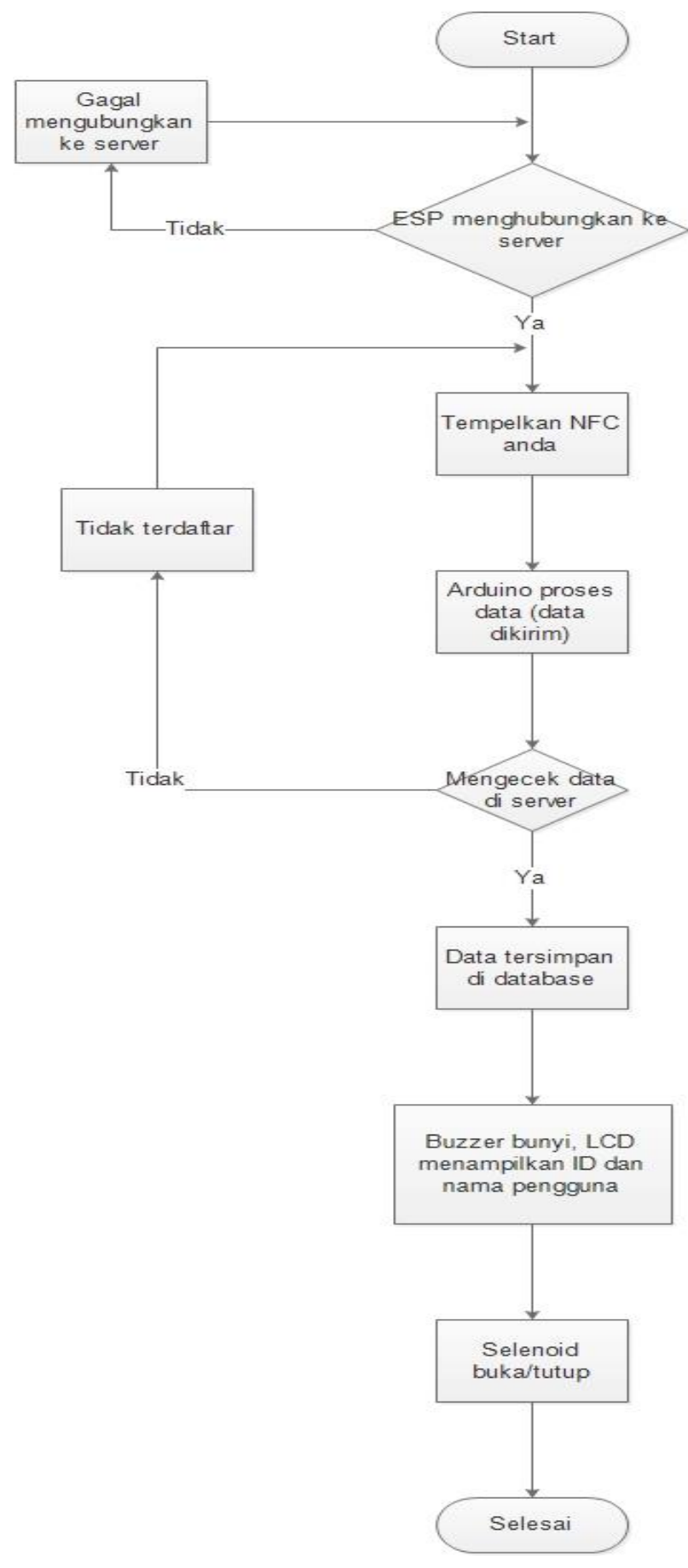

Gambar 4. Diagram Alir cara kerja sistem

Penjelasan dari diagram alir sistem Pertama mikrokontroler otomatis mencari akses point dan menghubungkan ke server,jika gagal maka ESP8266 secara otomatis tetap mencari akses point sesuai yang telah di program. jika ya maka tampilan di LCD menunjukkan tulisan Tempelkan NFC anda selanjutnya arduino memproses data (data dikirim ke server) mengecek data di server jika ya maka data tersimpan dalam database lcd menampilkan id dan nama pengguna buzzer bunyi dan selenoid terbuka/tertutup, jika tidak maka LCD bertuliskan tidak terdaftar.

\section{G. Perancangan database}

Database yang digunakan dalam sistem menggunkan database berformat sql dibuat menggunakan $p h p$ my admin. Dibawah ini adalah penjelasan dari masing-masing tabel yang di bangun.

1. Table name : $\log \mathrm{nfc}$

Pada tabel $\operatorname{lognf} c$ berisi history user menscan tag nfc ke reader dan juga waktu user masuk dan keluar ruangan.

Tabel 1. Lognfc

\begin{tabular}{|l|l|l|l|}
\hline & Column name & Data type & Allow Nulls \\
\hline $\begin{array}{l}\text { Primarykey } \\
\text { unique }\end{array}$ & No & Int & \\
\hline & Idnfc & Varchar(255) & $\checkmark$ \\
\hline & Nama & Varchar(255) & $\checkmark$ \\
\hline & Jabatan & Varchar(255) & $\checkmark$ \\
\hline & Jam masuk & Varchar(255) & \\
\hline & Jam keluar & Varchar(255) & \\
\hline & & & \\
\hline
\end{tabular}

2. Tabel name : nfc data

Pada tabel nfc data berisi data id nfe yang telah di daftar sebelumnya

Tabel 2. nfc data

\begin{tabular}{|l|l|l|l|}
\hline & Column name & Data type & Allow Nulls \\
\hline $\begin{array}{l}\text { Primarykey } \\
\text { Nnique }\end{array}$ & No & Int & \\
\hline & IdNFC & Varchar(255) & $\checkmark$ \\
\hline & Nama & Varchar(255) & $\checkmark$ \\
\hline & Jabatan & nvarchar(50) & $\checkmark$ \\
\hline & Jam masuk & Time & \\
\hline & Jam keluar & Time & \\
\hline & Mulaijam & Varchar(20) & \\
\hline & Akhirjam & & \\
\hline
\end{tabular}

\section{H. Pembuatan Prototype NFC}

Langkah pertama yang dilakukan adalah membangun prototype NFC. Pada tahap ini, peneliti merangkai sambungan mulai dari mikrokontroler ke NFC reader, LCD, Buzzer, ESP 8266, Relay, dan Selenoid DoorLock. Untuk mempermudah penyambungan, maka digunakan PCB (Printed Circuit Board) untuk penyambungan antara Arduino dan LCD menggunakan kabel jumper. Penyambungan keseluruhan komponen disajikan dalam bentuk wiring diagram dan dapat dilihat pada gambar 5 . 


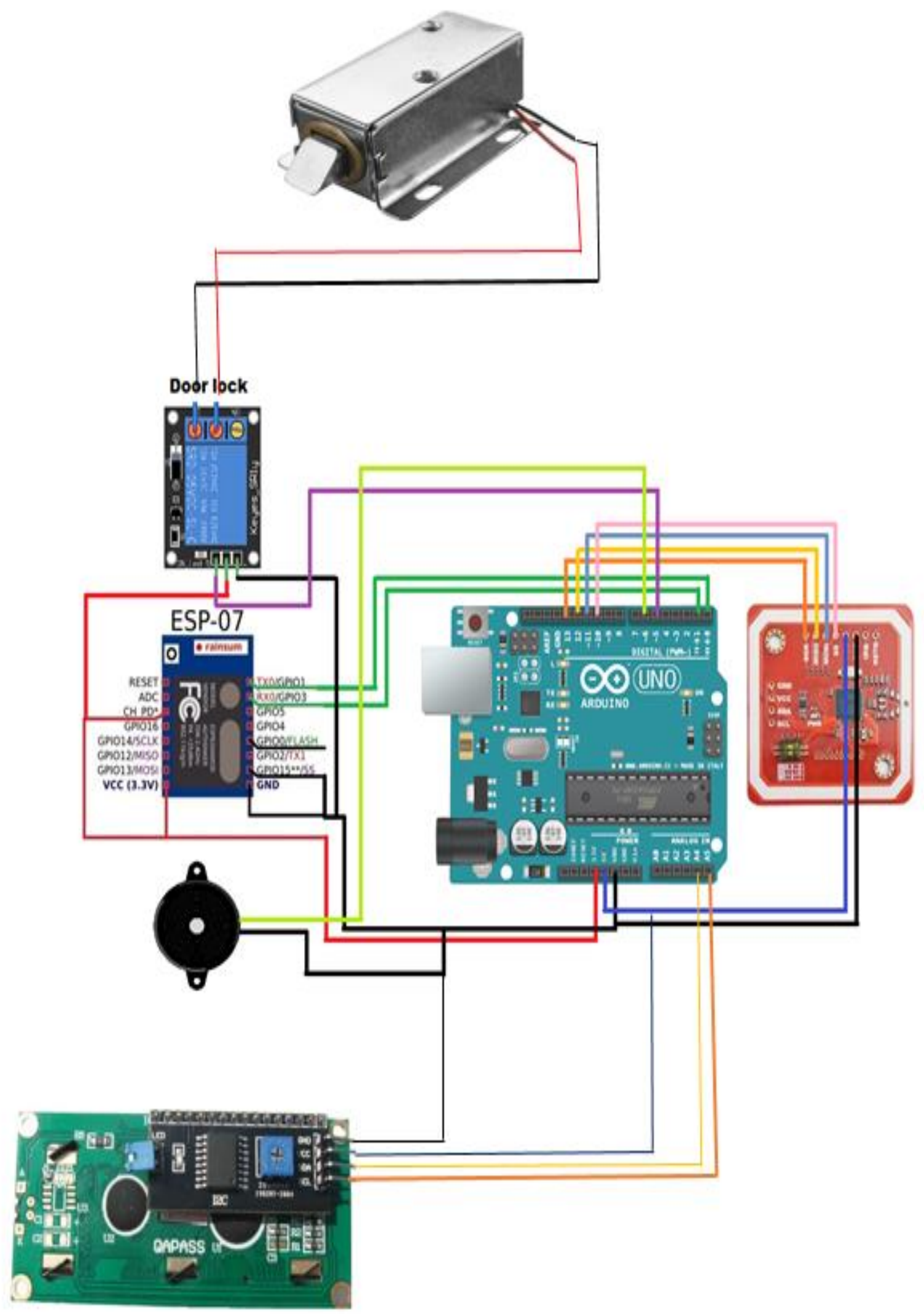

Gambar 5. Penyambungan keseluruhan prototype 
Rangkian prototype menggunakan alat asli bisa dilihat pada gambar dibawah ini :

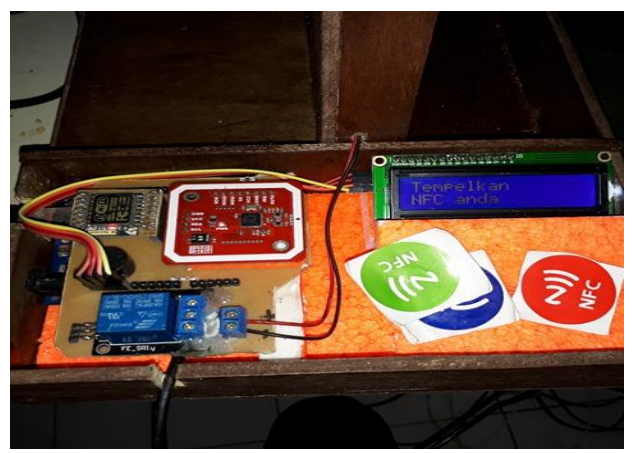

Gambar 6. Gambar alat setelah dirangkai

Gambar tampilan webserver dapat dilihat di bawah ini :

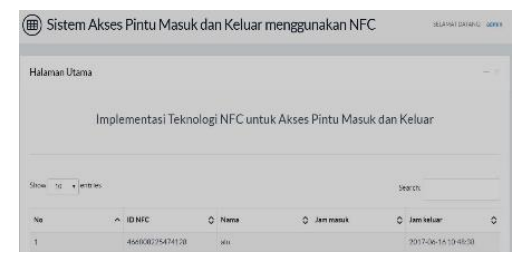

Gambar 7. Tampilan web server

\section{HASIL DAN PEMBAHASAN}

\section{A. Pengujian Sistem}

Setelah modul NFC dan Aplikasi sudah dibangun, langkah selanjutnya adalah melakukan pengujian sistem keseluruhan. Penulis akan mencoba menggunakan sampel kartu NFC tag, baik yang sudah didaftarkan, maupun yang belum didaftarkan untuk melihat respon dari aplikasi ke arduino.

a. Pengujian sampel tag (Terdaftar)

Berikut ini merupakan pengujian sampel yang pertama, yaitu kartu NFC tag. NFC tag akan didekatkan ke reader NFC untuk melihat apakah id sudah terdaftar ke dalam sistem atau belum terdaftar. Jika id tag berhasil terbaca, maka arduino akan memberi respon balik atas data NFC yang sudah diterima. Sebelum kartu di dekatkan didekatkan pada reader. admin harus login di web server dengan alamat domain : AhmadsadikNFCskripsi.com . dan memasukkan username : "admin" dan password : "admin" kemudian dekatkan tag pada reader seperti gambar dibawah ini :

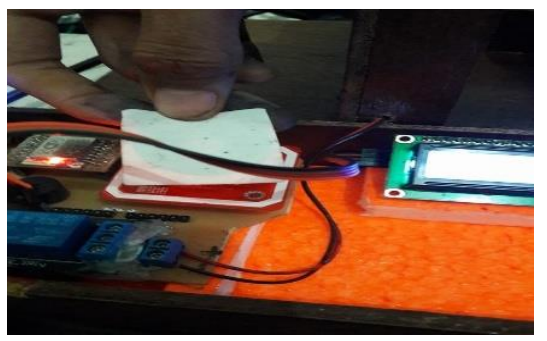

Gambar 8. NFC tag didekatkan pada reader
Setelah kartu didekatkan pada reader, maka modul NFC akan menerjemahkan data id tag dan mengirimkannya ke arduino untuk di proses. Lalu kemudian mikrokontroler akan mengirim data tersebut ke web server untuk diproses ke dalam database. Setelah data dikirim, maka data akan dicocokan dengan database apakah id tersebut sudah terdaftar di dalam database. Apabila id terdaftar maka server mengirim balik data tersebut ke mikrokontroler, kemudian mikrokontroler memproses dengan tampilan di LCD id dan nama pengguna kemudian solenoid terbuka kemudian admin dapat mengetahui siapa yang masuk atau keluar pada saat itu tergantung mode yang dipilih. Berikut adalah gambar di saat solenoid terbuka atau tertutup dan tampilan di web server siapa yang masuk atau keluar pada jam tersebut.

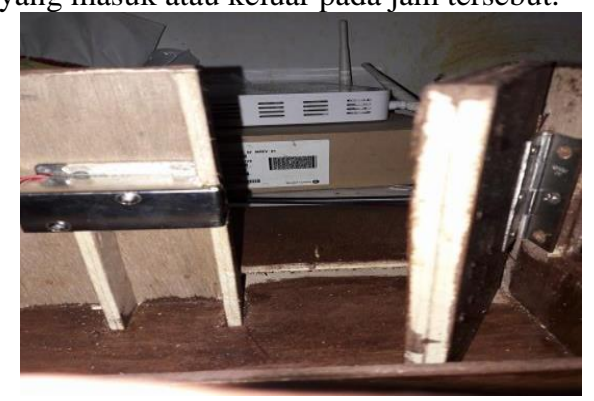

Gambar 9. Selenoid Terbuka

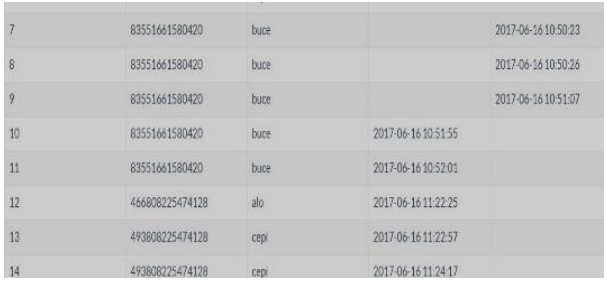

Gambar 10. Tampilan di web server user yang masuk

Penjelasan pada gambar 10. Admin dapat mengetahui id tag NFC dan user dengan nama (Alo) memasuki ruangan pada tanggal 16-06-2017 jam 11:22:57. Apabila user dengan nama (Alo) mau keluar ruangan maka admin atau user tersebut harus mengganti mode dari masuk menjadi keluar melalui form mode yang telah disediakan gambar bisa dilihat dibawah ini :

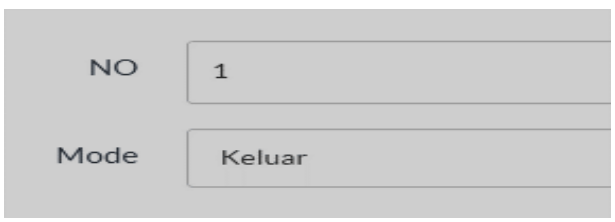

Gambar 11. Tampilan mengganti mode

Setelah mode diganti jadi keluar, untuk mengunci pintu user mendekatkan tag NFC ke reader kemudian mikrokontroler memproses seperti yang telah dijelaskan di atas dan solenoid akan terkunci seperti pada gambar dibawah ini : 


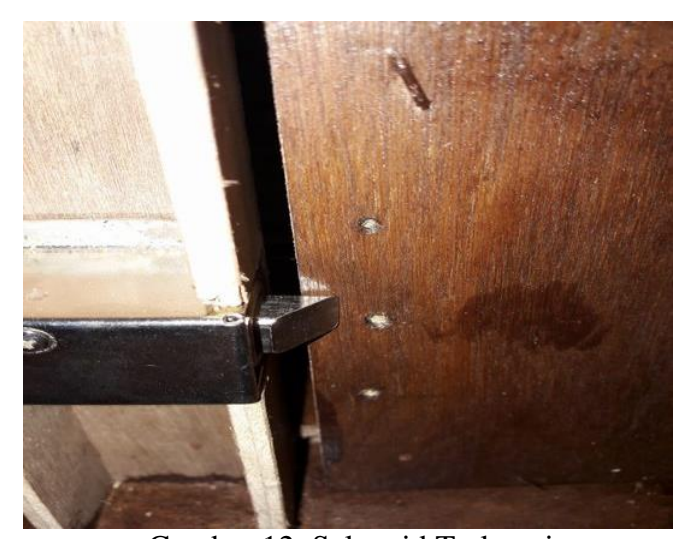

Gambar 12. Selenoid Terkunci

Kemudian web server menunjukan waktu dan tanggal user dengan nama (alo) keluar seperti gambar dibawah ini :

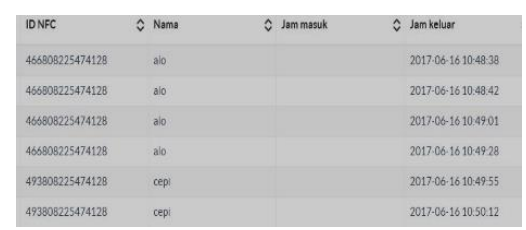

Gambar 13. Tampilan di web server user keluar

b. Pengujian sampel NFC tag (Tidak Terdaftar)

Pengujian sampel kedua adalah menggunakan tag lain yang. Tag NFC akan di dekatkan ke reader untuk melihat informasi apakah tag sudah terdaftar ke dalam database. Setelah kartu didekatkan ke reader, mikrokontroler memberi respon error bahwa id tidak terdaftar di dalam database, ketika database tidak menemukan id tag maka solenoid tak terbuka dan tulisan di LCD "Tidak terdaftar" dan nomor id tag tersebut.

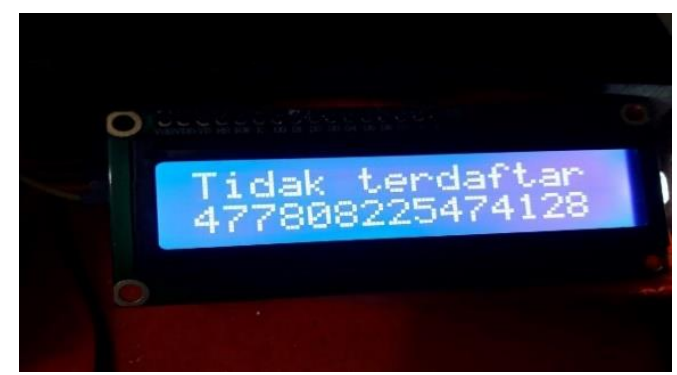

Gambar 14. Tampilan di lcd id tidak terdaftar.

c. Pengujian sampel tag menggunakan waktu akses tertentu.

Pengujian sampel ketiga adalah menggunakan tag yang terdaftar pada server yang telah di setting hanya bisa masuk atau keluar ruangan pada jam yang telah di set pada server. Misalkan sebuah id tag dengan nama alo hanya bisa akses masuk atau keluar ruangan pada jam 8 sampe 10, maka alo hanya bisa masuk pada jam tersebut, apabila belum jam atau sudah lewat jam tersebut alo tidak bisa akses masuk atau keluar ruangan lagi.

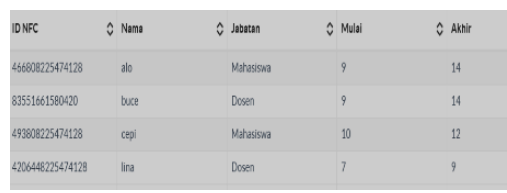

Gambar 15. Tampilan id yang terdaftar dengan waktu batas akses

d. Pengujian waktu terbacanya NFC tag dan dikirim ke server

Pengujian ini dilakukan untuk mengetahui waktu saat NFC tag di scan dan id dikirim ke server, tes yang dilakukan bisa dilihat pada tabel dibawah ini :

Tabel 3. Kecepatan id nfc saat dikirim ke server

\begin{tabular}{|l|l|}
\hline Waktu & Kecepatan id nfc saat dikirim ke server \\
\hline $09: 00$ & $4-5$ detik \\
\hline $12: 00$ & 5 detik \\
\hline $15: 00$ & 6,5 detik \\
\hline $18: 00$ & $5-6$ detik \\
\hline $21: 00$ & 6,5 detik \\
\hline $00: 00$ & $6-7$ detik \\
\hline
\end{tabular}

Dari hasil tabel di atas maka didapatkan kesimpulan bahwa kecepatan id NFC saat dikirim ke server tidak menentu, bisa 4 detik bisa juga 7 detik bahkan lebih tergantung dari konektsi internet yang terhubung.

e. Pengujian NFC tag dan penghalang pada reader.

Pengujian ini dilakukan untuk mengetahui saat NFC tag discan pada reader dan ada penghalang di reader, apakah terbaca atau tidak. Bahan-bahan yang digunakan adalah Kertas, Plastik, Besi, Kaca Mika, Kasing hp berbahan bahan karet. Hasil pengujian dapat dilihat pada tabel dibawah ini :

Tabel 4. NFC tag dan penghalang pada reader

\begin{tabular}{|l|l|}
\hline Bahan & Terbaca di tag atau tidak \\
\hline Kertas & Terbaca \\
\hline Plastik & Terbaca \\
\hline Besi & Tidak Terbaca \\
\hline Kaca Mika & Terbaca \\
\hline Karet Tebal & Tidak Terbaca \\
\hline Kaca Tranparan tebal & Tidak Terbaca \\
\hline Kain & Terbaca \\
\hline
\end{tabular}

Kesimpulan dari pengujian di atas adalah meskipun ada penghalang tag dapat merespon reader, kecuali beberapa penghalang tertentu yang agak tebal maka reader tidak akan merespon saat tag discan. 


\section{PENUTUP}

A. Kesimpulan

Setelah melakukan penelitian ini maka dapat diambil kesimpulan :

1. Sistem ini memerlukan waktu kurang lebih $4-5$ detik untuk membaca data id dan mengirim ke server.

2. Sistem dapat mengetahui waktu user yang masuk dan keluar ruangan melalui web server.

3. Pada saat tag discan dan data dikirim ke server, apabila data tersebut terdaftar maka solenoid terbuka / tertutup, jika id yang discan pada tag tidak terdaftar maka solenoid tidak terbuka.

4. Jika koneksi internet tidak stabil maka pengiriman data ke server sangat lama atau gagal.

5. Meskipun ada penghalang pada reader saat nfc tag di scan reader dapat merespon kecuali ada penghalang tertentu seperti bahan karet tebal maka reader tidak dapat merespon tag yang discan.

B. Saran

1. Tampilan GUI diperluas lagi untuk dapat menampilkan informasi lebih bnyak dan jelas.

2. Prototype dapat di implementasikan langsung secara real, agar dapat digunakan untuk user yang membutuhkan.

3. Menambah fitur saat mengakses masuk dan keluar secara otomatis, tak perlu lagi mengubah mode secara manual.

4. Menambah fitur membuka pintu dari web server melalui halaman admin.

\section{DAFTAR PUSTAKA}

[1] Abdul Kadir (2015). Buku Pintar Pemrograman Arduino. Cetakan Pertama. Penerbit MediaKom Yogyakarta Indonesia.

[2] Andrianto Heri, Darmawan Aan. Arduino belajar cepat dan Pemrograman Penerbit Informatika

[3] Danta, Bravera “Implementasi Teknologi RFID untuk Identifikasi dan Autentikasi pada Gerbang Masuk di Universitas Sam Ratulangi Manado" Skripsi Tugas Akhir.

[4] Hidayatullah Fahmi, Sunaryono Dwi, Hariadi Ridho Rahman. "Rancang Bangun Sistem Keamanan Keluar Masuk Parkir dengan Kartu cerdas Mifare dan Teknologi Near Field Communication (NFC) Studi kasus Parkir Jurusan Teknik Informatika". Skripsi Tugas Akhir

[5] Kontu H.F. Ryan , "Perancangan Sistem Pembaca Surat Tanda Nomor Kendaraan Dengan Teknologi NFC' Skripsi Tugas Akhir

[6] Qonnita Aisyah,Soraya.Michrandi Nasution,Surya. Nugroho Jati,Agung. "Perancangan Implementasi Sistem Akses Kontrol pada Pintu Berbasis Teknologi Near Field Communication dengan Mikrokontroler Arduino Uno”. Skripsi tugas akhir

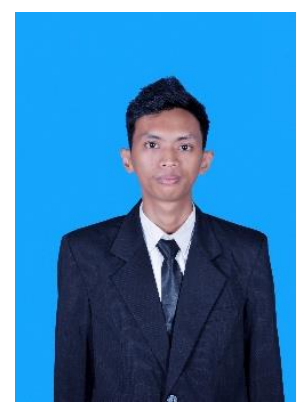

SEKILAS TENTANG PENULIS

Saya bernama Ahmad Sadik

Djamar . Lahir pada tanggal 16

Desember 1994 di Manado.

Saya mulai menempuh pendidikan di SD Inpres Banda Neira (2000-2006). Kemudian melanjutkan ke SMP N 2 Bacan (2006-2009). Setelah itu saya menempuh pendidikan di SMA N 1 Bacan (2009-2012). Setelah lulus, di tahun 2012 saya melanjutkan pendidikan di Universitas Sam Ratulangi Manado, mengambil Program Studi S-1 Teknik Informatika di Jurusan Elektro Fakultas Teknik. Selama masa kuliah, saya menjalani kerja praktek di kantor PTI UNSRAT. 